\title{
Qualidade da Forragem e dos Componentes de Híbridos de Milho de Diferente Degradabilidade da Matéria Seca
}

\author{
José Luiz de Andrade Rezende Pereira ${ }^{1}$ Renzo Garcia Von Pinho ${ }^{2}$ Alano Xavier Souza Filho ${ }^{3}$, Álvaro de Oliveira \\ Santos ${ }^{4}$ e Rodolfo Goulart Fonseca ${ }^{5}$
}

\begin{abstract}
1FSULDEMINAS Campus Inconfidentes, email: jose.pereira@ifs.ifsuldeminas.edu.br ${ }^{2}$ Universidade
Federal de Lavras, Departamento de Agricultura, Cep. 37.200-000, Caixa postal 37, Lavras, MG, renzo@ufla.br, ${ }^{3}$ alanofilho@hotmail.com,,alvaroareado@yahoo.com.br, ${ }^{5}$ rodolfogoulart0214@yahoo.com.br
\end{abstract}

\section{RESUMO}

O objetivo deste trabalho foi avaliar a qualidade da forragem e dos componentes de híbridos de milho de alta e baixa degradabilidade da matéria seca em três épocas de corte e em duas épocas de semeadura. Oito híbridos de milho de diferentes características agronômicas reunidos em grupos de alta degradabilidade (DEG) da matéria seca e baixa degradabilidade da matéria seca foram avaliados em dois experimentos com semeadura realizada em 11/11/2007 (NOV) e 12/12/2007 (DEZ) sob sistema convencional de cultivo. Os híbridos foram colhidos em três estádios de maturação dos grãos, meia linha de leite $(1 / 2 \mathrm{LL})$, três quartos da linha de leite $(3 / 4 \mathrm{LL}) \mathrm{e}$ camada negra $(\mathrm{CN})$. $\mathrm{O}$ avanço na maturidade afeta a degradabilidade (DEG), fibra em detergente neutro (FDN) e FDN degradável da planta inteira e seus componentes, exceto para FDN degradável de colmo. O grupo de alta degradabilidade da matéria seca apresenta melhores valores de DEG, FDN e FDN degradável para todos os componentes exceto FDN de palha, FDN degradável de folha e FDN degradável de palha que não apresentaram diferenças entre os grupos avaliados. A interação não significativa entre grupos $\mathrm{x}$ épocas de corte para todas as variáveis evidencia a melhor qualidade dos híbridos de alta degradabilidade da matéria seca com o avanço da maturidade da planta. $\mathrm{O}$ atraso na semeadura afetou a degradabilidade dos componentes folhas, palhas e grãos, além dos teores de FDN de palha, sabugo e FDN degradável de folha, porém não alterou os parâmetros associados à planta inteira.

Palavras-chaves: Zea mays, degradabilidade da matéria seca.

\section{Quality of the Forage and of the Components of Hybrids of Corn of Different Degradability of the Dry Matter}

\begin{abstract}
The objective of this work was to evaluate the quality of the forage and of the components of hybrids of discharge corn and low degradability of the dry matter in three cut times and in two sowing times. Eight hybrid of corn of different agronomic characteristics gathered in groups of high degradability (DEG) of the matter it dries and low degradability of the matter dries were appraised in two experiments with sowing accomplished in 11/11/2007 (NOV) and 12/12/2007 (DEC) under conventional system of cultivation. The hybrids were picked at three stadiums of maturation of the grains, stocking line of milk $(1 / 2 \mathrm{LL})$, three forth of the line of milk $(3 / 4 \mathrm{LL})$ and black layer $(\mathrm{CN})$. The progress in the maturity affects the degradability (DEG), fiber in neutral detergent (FDN) and FDN degradability of the whole plant and their components, except for FDN stem degradability. The group of high degradability of the matter dries presents better values of DEG, FDN
\end{abstract}


and FDN degradability for all the components except straw FDN, FDN leaf degradability and FDN straw degradability that didn't present differences among the appraised groups. The interaction no significant among groups $\mathrm{x}$ cut times for all the variables evidence the best quality of the hybrids of high degradability of the matter dries with the progress of the maturity of the plant. The delay in the sowing affected the degradability of the components leaves, straws and grains, besides the tenors of straw FDN, cob and FDN leaf degradability; however it didn't alter the parameters associated to the whole plant.

Key words: Zea mays, degradability dry matter

\section{INTRODUÇÃO}

Até bem pouco tempo atrás, uma das maneiras de se avaliar a qualidade da silagem de milho era realizada por meio da porcentagem de grãos na matéria seca. Isto ocorreu devido ao grande número de trabalhos, desenvolvidos até a década de 70 que demonstravam que os grãos de milho são mais digestíveis do que as folhas e hastes da planta e conseqüentemente o aumento de sua proporção na silagem favoreceria um aumento na qualidade do volumoso (Silva, 1997; Allen et al., 2003). Entretanto com o avanço dos trabalhos de pesquisa foram surgindo novos parâmetros de avaliação da qualidade da forragem. Shaver (2006) destaca a evolução nas avaliações da silagem que eram baseadas exclusivamente em teores de fibras (FDA e FDN) e passaram a serem baseadas em digestibilidade de fibras, proteínas, ácidos graxos, carboidratos não fibrosos e amido. Alguns autores sugerem ainda que somados a fatores relacionados a qualidade dos grãos a qualidade da forragem também está ligada a proporção e a qualidade dos componentes morfológicos (Beleze et al.,. 2003; Tang, et al. 2008).

Os componentes colmo, folha, pa- lhas e sabugo correspondem em média a 70\% do total de matéria seca da planta (Caetano, 2001). A qualidade da forragem está associada a fatores genéticos, porém a sua redução pode ser confundida com efeitos de clima e principalmente maturidade da planta. Lavezzo et al. (1997) ao avaliar híbridos de milho em quatro estádios de maturidade verificaram tendências nas reduções de folhas e um aumento percentual de espigas, porém diversos trabalhos demonstram a perda da qualidade da forragem com o avanço da maturidade da planta (Tolera e Sundstùlc, 1999; Jung e Casler, 2006; Kruse et al., 2008). Beleze et al. (2003) observaram alterações na participação das frações na matéria seca e definiram ainda que os melhores coeficientes de digestibilidade estão entre $30 \%$ a $38 \%$ de matéria seca, sendo que em estágios mais avançados a perda da qualidade foi devido a redução na qualidade das frações vegetativas.

Além dos fatores genéticos e edafoclimáticos que podem interferir na qualidade da forragem de milho há relatos na literatura que o atraso da semeadura pode provocar redução na degradabilidade na matéria da forragem diminuindo sua qualidade (Gomes et al, 2004).

Estudos sobre a qualidade dos componentes e da forragem são escassos com híbridos tropicais, assim como sua interação com a época de semeadura. Deste modo este trabalho teve como objetivo avaliar a qualidade da forragem e dos componentes de híbridos de milho de alta e baixa degradabilidade da matéria seca em três épocas de corte e em duas épocas de semeadura.

\section{MATERIAL E MÉTODOS}

Oito híbridos de milho de diferentes características agronômicas reunidos em grupos de alta degradabilidade da matéria seca da fração vegetativa (P30F90, NB7315, DOW2B710 e AG4051) e baixa degradabilidade da matéria seca da fração vegetativa (DOW2A525, 
AG1051, AG5011 e DOW2C577) foram utilizados para realização dos experimentos (Tabela 1).

O trabalho foi conduzido em área experimental do Departamento de Agricultura da Universidade Federal de Lavras, situada na cidade de Lavras, MG em solo classificado como Latossolo Vermelho distroférrico (LVdf), textura argilosa e declividade de 9\%. O município de Lavras está situado a $920 \mathrm{~m}$ de altitude, a $21^{\circ} 14$ de latitude Sul e $45^{\circ} 00$ de latitude Oeste. O clima da região é do tipo temperado propriamente dito, ou seja, mesotérmico de inverno seco $(\mathrm{Cwb})$. Apresenta temperatura média anual de $19,3^{\circ} \mathrm{C}$ e precipitação média anual de $1.411 \mathrm{~mm}$.

Foram conduzidos dois experimentos com semeadura realizada em 11/11/2007 (NOV) e 12/12/2007 (DEZ) sob sistema convencional de cultivo. As oito cultivares de milho foram colhidas em três estádios de maturação dos grãos, meia linha de leite $(1 / 2 \mathrm{LL})$, três quartos da linha de leite $(3 / 4 \mathrm{LL})$ e camada negra $(\mathrm{CN})$.
Cada parcela foi constituída de seis linhas de cinco metros de comprimento espaçadas de $80 \mathrm{~cm}$, sendo a área total de $24 \mathrm{~m}^{2}$. As duas linhas centrais foram consideradas como área útil de cada parcela para efeito de coleta de dados. Um desbaste foi feito quando as plantas estavam com 2 a 3 folhas totalmente expandidas com a finalidade de se obter um estande final de 60000 plantas ha-1.

A adubação de plantio foi de $400 \mathrm{~kg}$ ha $^{-1}$ da fórmula $08-28-16+0,5 \%$ de zn. A adubação de cobertura foi realizada quando as plantas estavam com 5 a 6 folhas totalmente expandidas utilizando $350 \mathrm{~kg} \mathrm{ha}^{-1} \mathrm{da}$ formulação 30-00-20. Para o controle das plantas invasoras foi utilizado, em pré-emergência, um herbicida a base de atrazine + metalaclor, além de uma aplicação de Antrazine na dosagem de $31 \mathrm{lha}^{-1}$ em pós emergência. Os outros tratos culturais e fitossanitários foram executados nas épocas adequadas, de acordo com a necessidade da cultura.

TABELA 1. Características das cultivares de milho utilizado nos experimentos.

\begin{tabular}{cccccc}
\hline HÍBRIDOS & TIPO $^{(1)}$ & CICLO $^{(2)}$ & TEXTURA DO GRÃO & USO $^{(4)}$ & $\begin{array}{c}\text { DEG24 DA FRAÇÃO } \\
\text { VEGETATIVA }\end{array}$ \\
\hline AG1051 & HD & Smp & Dent & G/SPI & BAIXA \\
AG4051 & HT & Smp & Dent & G/SPI & ALTA \\
AG5011 & HT & P & Dent & G/SPI & BAIXA \\
DOW2C577 & HS & P & SMDent & G & BAIXA \\
P30F90 & HS & P & D & G/SPI & ALTA \\
NB7315 & HS & P & D & G & ALTA \\
DOW2A525 & HS & P & SMD & G & BAIXA \\
DOW2B710 & HS & P & SMD & G & ALTA \\
\hline
\end{tabular}

(1) HS - Híbrido simples; HT - Híbrido triplo; HD - Híbrido duplo

(2) Smp - semiprecoce; $\mathrm{P}$ - precoce.

(3) D - Duro; SMDent - Semidentado; SMD - Semi duro, Dent - Dentado

(4) G - Grãos; SPI - silagem de planta inteira.

Na colheita da forragem, as plantas das duas linhas centrais das parcelas foram cortadas a $20 \mathrm{~cm}$ do solo, quando os grãos das espigas de cada híbrido apresentavam-se no respectivo estádio de maturação de interesse $(1 / 2 \mathrm{LL}, 3 / 4 \mathrm{LL}$ e CN). Quinze plantas de cada parcela foram tomadas ao acaso e fracionadas em colmo (C), folha $(\mathrm{F})$, palha $(\mathrm{P})$, sabugo $(\mathrm{S})$ e grãos $(\mathrm{G})$. Outras quinze plantas de cada parcela também foram tomadas ao acaso e utilizadas para compor a amostra de planta inteira (PI).Uma amostra da planta inteira e de cada fração da planta, 
de aproximadamente $0,6 \mathrm{~kg}$ foi seca em estufa de ventilação forçada a $55^{\circ} \mathrm{C}$ até atingir peso constante. Após a secagem as amostras secas a $55^{\circ} \mathrm{C}$ foram moídas em moinho tipo Willey, com peneira de $5 \mathrm{~mm}$ para a condução do ensaio de degradabilidade in situ da matéria seca, exceto para os grãos que foram cortados na metade ainda congelados Para avaliação da degradabilidade in situ foram utilizadas três vacas com cânula ruminal, uma da raça Jersey, não-lactante e não-gestante e duas da raça Holandesa lactantes e não gestantes. Duas semanas antes do início das incubações e durante o período experimental os animais receberam uma dieta composta de silagem de milho ad libitum, $3 \mathrm{~kg}$ (vaca Jersey) e $6 \mathrm{~kg}$ (vacas holandesas) de concentrado à base de milho e farelo de soja em duas alimentações diárias.

A degradabilidade in situ da matéria seca da planta inteira e das frações (colmo, folha, palha, sabugo e grãos) foi determinada segundo metodologia descrita por Pereira (1997).

A FDN e FDN degradável foram realizadas por análise não sequencial utilizando-se digestor rápido para fibra em sacos, marca Marconi modelo MA-444, e solução de detergente neutro descrita por Van Soest et al. (1991). Os sacos utilizados foram de tecido não tecido (TNT) de densidade 100g.dm-3. A FDN degradável foi calculada pelo desaparecimento da FDN expresso em porcentagem com base na FDN inicial.

O delineamento experimental utilizado foi o de blocos casualizados com três repetições. Realizou-se, portanto uma análise de variância conjunta envolvendo as três épocas de corte e as duas épocas de semeadura.

As médias geradas pelo pacote LSMEANS foram agrupadas em híbridos de alta e baixa degradabilidade da matéria seca, a partir daí uma outra análise utilizando o proc. GLM foi gerada. dois contrastes ortogonais com 1 grau de liberdade foram testados para a época de corte: efeito linear de maturação (1/2 LL versus $\mathrm{CN})$ e efeito quadrático de maturação (1/2 LL versus $3 / 4 \mathrm{LL}+\mathrm{CN})$.
Pela análise conjunta foi observado efeito significativo $(\mathrm{p}<0.05)$ das fontes Grupos, para todas as variáveis avaliadas, com exceção para os teores de FDN de palha e FDN degradável das frações folha, palha e sabugo. As Épocas de Corte influenciaram $(p<$ $0,05)$ todas variáveis exceto FDN degradável de colmo. As Épocas de Plantio não tiveram efeito significativo $(p<0.08)$ para as variáveis degradabilidade da planta inteira e sabugo, teores de FDN da planta inteira e folha, bem como FDN degradável da planta inteira e das frações colmo e palha. Porém as demais variáveis avaliadas tiveram efeito significativo para esta fonte. As interações GRUPOS x EC, G x ES e G x EC x ES não tiveram efeito sobre nenhuma variável analisada, ao passo que as variáveis degradabilidade da fração folha, palha e sabugo e FDN degradável de colmo, folha, palha e sabugo sofreram efeito significativo $(p<0.08)$ da interação EC x ES.

A degradabilidade da planta inteira apresentou médias de $55 \%$ para o grupo de alta e 50,6\% para o grupo de baixa e um erro padrão da média de 0,42 (Tabela 2). Quanto as épocas de corte os valores na $1 / 2 \mathrm{LL}, 3 / 4 \mathrm{LL}$ e CN no grupo de alta foram respectivamente $55 \%, 53,4 \%$ e $50,4 \%$. Já no grupo de baixa esses valores foram $53 \%, 52,6 \%$ e $49,6 \%$. Considerando a média dos dois grupos os valores na $1 / 2$ LL, $3 / 4$ LL e CN foram $54,06 \%, 53,05 \%$ e $49,92 \%$, respectivamente. Estes valores apresentam um efeito linear do decréscimo da degradabilidade da planta inteira (Tabela 3). A degradabilidade da planta inteira é maior no grupo de alta degradabilidade da fração vegetativa em todas as épocas de corte analisadas (Tabela 3). Este comportamento demonstra a importância da degradabilidade da planta inteira e da fração vegetativa no posicionamento de um híbrido para a produção de silagem.

O grupo de alta degradabilidade da matéria seca teve $21,97 \%$ da matéria seca da fração vegetativa degradada, enquanto que o de baixa teve $18,87 \%$ da matéria seca degra- 
dada. Esta variável apresentou um erro padrão da média de 0,44 (Tabela 2). O plantio realizado em novembro teve $21,54 \%$ na matéria seca da fração vegetativa degradada enquanto que o plantio realizado em dezembro teve $19,30 \%$. $\mathrm{O}$ atraso na semeadura provocou uma redução de 2,24 unidades percentuais na degradabilidade da matéria seca da fração vegetativa.

A degradabilidade média do colmo foi de $38,60 \%$ para o grupo de alta e 31,06\% para o grupo de baixa (Tabela 2). A diferença entre os grupos foi de 7,54 unidades percentuais, a maior encontrada entre todas as variáveis que compõem a fração vegetativa (Tabela 2). $\mathrm{Na}$ época de corte 1/2 LL a degradabilidade média do colmo foi de $37,69 \%$, sendo significativamente diferente de $36,27 \%$ da época de corte $3 / 4$ LL e de $30,52 \%$ da CN.

No plantio realizado em novembro os valores para degradabilidade da folha foram $50,38 \%$, $40,86 \%, 36,64 \%$ para $1 / 2$ LL, $3 / 4$ LL e $C N$, enquanto que para o plantio realizado em dezembro estes valores foram $44,47 \%, 38,32 \%$ e $35,30 \%$ para $1 / 2 \mathrm{LL}$,
3/4 LL e CN, respectivamente (Tabela 3).

Para a fração palha as médias da degradabilidade para os grupos de alta e baixa foram respectivamente $36 \%$ e $33,8 \%$ (Tabela $2)$. Quanto as épocas de corte os valores para $1 / 2$ LL, $3 / 4$ LL e CN no grupo de alta foram respectivamente $43,4 \% 33,4 \%$ e $31 \%$. Já no grupo de baixa esses valores foram de 39,4\%, 32,2\% e $29,6 \%$. Apresentando estes decréscimos um comportamento quadrático (Tabela 3). Quanto as épocas de corte para semeadura em novembro os valores de degradabilidade da fração palha na $1 / 2 \mathrm{LL}, 3 / 4 \mathrm{LL}$ e $\mathrm{CN}$ foram respectivamente $44,6 \%, 35,75 \%$ e $30,85 \%$. Já para época de plantio em dezembro esses valores foram de $38,3 \%, 29,9 \%$ e $29,8 \%$. Estes valores demonstram que a palha na $1 / 2$ LL é de melhor qualidade que em 3/4 LL e CN. Verbic et al. (1995) encontraram variações entre híbridos de 39\% a $45 \%$ para degradabilidade in vitro e $73 \%$ a $79 \%$ para teores de FDN de palha de híbridos colhidos na meia linha de leite. Estes valores coincidem com os encontrados neste trabalho.

TABELA 2. Degradabilidade média (DEG), fibra em detergente neutro (FDN) e fibra em detergente neutro degradável (FDND) da fração vegetativa (VEG), planta inteira (PI), colmo (C), folha (F), palha (P), sabugo(S) e grão(G), dos grupos de alta e baixa degradabilidade da fração vegetativa.

\begin{tabular}{ccccc}
\hline \multirow{2}{*}{ Variáveis } & \multicolumn{3}{c}{ Grupos } & EPM \\
\cline { 2 - 4 } & ALTA & $\ldots \ldots . . . \% \ldots \ldots$ & BAIXA & 0,44 \\
DEGVEG & 21,97 & & 18,87 & 0,42 \\
DEGPI & 55 & 50,69 & 1,18 \\
DEGC & 38,6 & 31,06 & 0,58 \\
DEGF & 42,67 & 39,32 & 0,72 \\
DEGP & 35,99 & 33,8 & 0,79 \\
DEGS & 28,65 & 25,52 & 0,4 \\
DEGG & 25,87 & 24,33 & 0,35 \\
FDNPI & 45,51 & 47,05 & 1,14 \\
FDNC & 72,36 & 78,83 & 0,63 \\
FDNF & 75,35 & & 78,25 & 0,77 \\
FDNP & 85,63 & 87,23 & 0,52 \\
FDNS & 85,58 & 87,8 & 0,43 \\
FDNDPI & 26,21 & 24,48 & 0,71 \\
FDNDC & 20,78 & 18,23 & 0,62 \\
FDNDF & 32,84 & 31,53 & 0,73 \\
FDNDP & 28,66 & 28,53 & 0,85 \\
FDNDS & 20,87 & 19,7 & 0,007 \\
DENS & & & & \\
\hline
\end{tabular}


$\mathrm{Na}$ avaliação da degradabilidade da fração sabugo os grupos de alta e baixa apresentaram médias de $28,5 \%$ e $25,5 \%$, respectivamente (Tabela 2). Quanto as épocas de corte os valores para $1 / 2 \mathrm{LL}, 3 / 4 \mathrm{LL}$ e $\mathrm{CN}$ no grupo de alta foram respectivamente $33,6 \% 28 \%$ e $24,2 \%$. Já no grupo de baixa esses valores foram de $30,8 \%, 25,9 \%$ e $19,8 \%$. Sendo esses decréscimos de comportamento linear (Tabela 3). Para a semeadura realizada em novembro a degradabilidade do sabugo apresentou médias de $28,7 \%, 27,5 \%$ e $24,8 \%$ para as épocas de corte $1 / 2 \mathrm{LL}, 3 / 4 \mathrm{LL}$ e CN, respectivamente. $\mathrm{Na}$ semeadura realizada em Dezembro os valores para $1 / 2 \mathrm{LL}, 3 / 4 \mathrm{LL}$ e CN foram de $35,7 \%$, $26,4 \%$ e $19,2 \%$. BELEZE (2003) reforça que percentagem de sabugo + palha é um dos fatores que contribuem para diminuição do valor nutritivo da forragem, já que ambos são constituídos de fibras de baixa qualidade. Neste trabalho a fração palha obteve resultados de degradabilidade e FDN degradável acima das frações colmo e sabugo, somente a fração folha teve qualidade superior a palha.

TABELA 3. Degradabilidade média (DEG), fibra em detergente neutro (FDN) e fibra em detergente neutro degradável (FDND) da fração vegetativa (VEG), planta inteira (PI), colmo (C), folha (F), palha (P), sabugo(S) e grão(G), dos grupos de alta e baixa degradabilidade da fração vegetativa para os grupos de alta e baixa degradabilidade da fração vegetativa nas três épocas de corte.

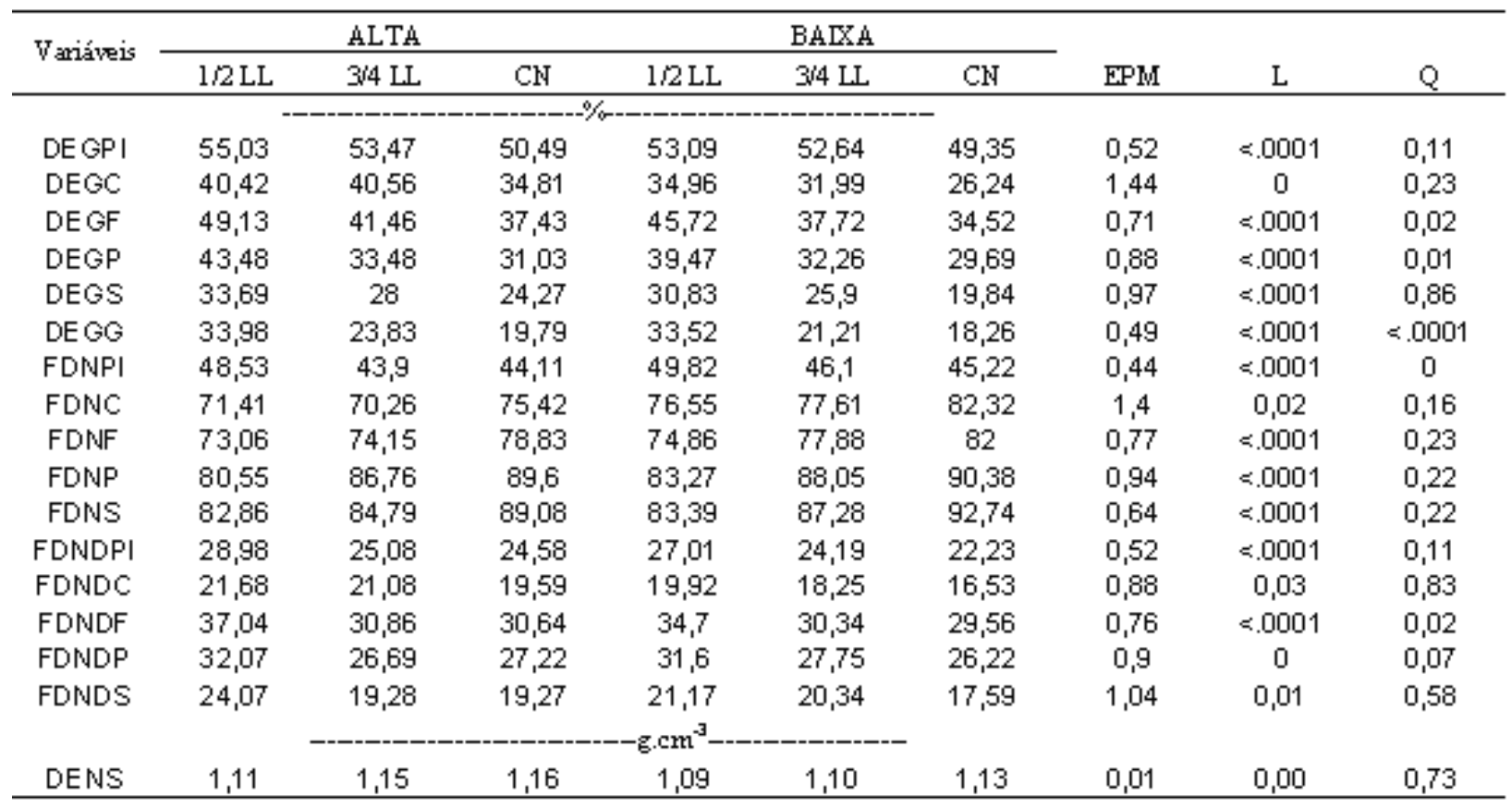

Para o componente grão os grupos de alta e baixa apresentaram médias de degradabilidade de $25,8 \%$ e $24,3 \%$ respectivamente (Tabela 2). Quanto as épocas de corte $1 / 2$ LL, $3 / 4$ LL e CN a degradabilidade do grão apresentou médias de $33,7 \%, 22,5 \%$ e $19 \%$, sendo esse decréscimo de comportamento quadrático (Tabela 3). A redução da degradabilidade do grão da $1 / 2$ LL para a $\mathrm{CN}$ foi de $14,1 \%$ no grupo de alta e de $15,26 \%$ no grupo de baixa. Vale ressaltar que os grãos duros perdem mais qualidade do que os dentados com o avanço da maturidade e esse decréscimo na degradabilidade do grão foram encontrados por outros autores (Corrêa, 2002 e Pereira, 2004). Na avaliação das épocas de plantio as médias para novembro e dezembro foram respectivamente $24 \%$ e $26,2 \%$

Para os teores de FDN da planta inteira os grupos de alta e baixa apresentaram médias de $45,5 \%$ e $47 \%$ (Tabela 2). Quanto as épocas de corte os valores para $1 / 2$ LL, $3 / 4$ LL e CN no 
grupo de alta foram respectivamente $48,5 \%$, $43,9 \%$ e $44,1 \%$, enquanto que no grupo de baixa esses valores foram de 49,8\%, 46,1\% e $45,2 \%$. Em média o FDN da planta inteira na $1 / 2$ LL, $3 / 4$ LL e CN foram de $49,17 \%, 45 \%$ e $44,6 \%$, respectivamente (Tabela 3 ).

Para a FDN de colmo as médias para os grupos de alta e baixa foram de $72,3 \%$ e $78,8 \%$, respectivamente (Tabela 2 ). No grupo de alta os valores na $1 / 2$ LL, $3 / 4$ LL e CN foram $71,41 \%, 70,26 \%$ e $75,42 \%$, respectivamente. No grupo de baixa os valores foram $76,55 \%$, $77,61 \%$ e $82,32 \%$ na $1 / 2$ LL, $3 / 4$ LL e CN respectivamente (Tabela 3). Considerando os dois grupos a média na $1 / 2$ LL, $3 / 4$ LL e CN foi de $73,98 \%, 73,93 \%$ e $78,87 \%$, respectivamente (Tabela 3 ).

Para os teores de FDN de folha os grupos de alta e baixa apresentaram médias de 75,35\% e 78,25\% (Tabela 2). Quanto as épocas de corte os valores para $1 / 2$ LL, $3 / 4$ LL e CN no grupo de alta foram respectivamente $73 \%, 74,1 \%$ e 78,8\%. Já no grupo de baixa esses valores foram de 74,8\%,77,8\% e $82 \%$.

Analisando a variável FDN de palha observou-se um incremento linear nos teores tanto para o grupo de alta degradabilidade da matéria seca quanto para os de baixa. No grupo de alta os teores foram $80,5 \% 86,7$ e $89,6 \%$ nas avaliações em $1 / 2$ LL, $3 / 4$ LL e CN. No grupo de baixa esses valores foram $83,3 \% 88 \% \mathrm{e}$ 90,3\% na $1 / 2$ LL, $3 / 4$ LL e CN (Tabela 3). Assim como para as frações colmo e sabugo o teor de FDN da fração palha foi diferente nas duas épocas de semeadura, apresentando médias de $83,9 \%$ e $90 \%$ para as semeaduras realizadas em novembro e dezembro respectivamente.

As médias para os teores de FDN da fração sabugo foram $85,5 \%$ e $87,8 \%$ para os grupos de altas e baixas degradabilidade da matéria seca (Tabela 2). Quanto as épocas de corte os valores para $1 / 2 \mathrm{LL}, 3 / 4 \mathrm{LL}$ e $\mathrm{CN}$ no grupo de alta foram respectivamente $82,8 \% 84,7 \%$ e $89 \%$. Já no grupo de baixa esses valores foram de $83,3 \%, 87,2 \%$ e $92,7 \%$. Sendo esse acrés- cimo de comportamento linear (Tabela 3). Quanto às épocas de semeadura os valores desta variável para novembro e dezembro foram respectivamente $84,6 \%$ e $88,7 \%$. O atraso da semeadura provocou aumento no teor de FDN de palha diminuindo sua qualidade.

Beleze (2003) reforça que percentagem de sabugo + palha é um dos fatores que contribuem para diminuição do valor nutritivo da forragem, já que ambos são constituídos de fibras de baixa qualidade. Estrada-Flores et al. (2006) também relatou aumento da FDN e perda da qualidade dos componentes palhas e sabugos devido ao atraso da semeadura corroborando assim com os resultados deste trabalho.

A FDN degradável da planta inteira apresentou valores de $26,2 \%$ e $24,8 \%$ para os grupos de alta e baixa respectivamente. Para as épocas de corte na $1 / 2 \mathrm{LL}, 3 / 4 \mathrm{LL}$ e $\mathrm{CN}$, no grupo de alta, os valores de FDN degradável da planta inteira foram $28,9 \%, 25 \%$ e $24,5 \%$. Já no grupo de baixa esses valores foram de $27 \%, 24,2 \%$ e $22,2 \%$, respectivamente. Considerando os grupos de alta e baixa os valores médios na $1 / 2$ LL, $3 / 4$ LL e CN foram $27,99 \%$, $24,63 \%$ e $23,4 \%$. O grupo de alta degradabilidade da matéria sempre manteve os teores mais altos de FDN degradável ao longo dos dias após o plantio, isto significa que o grupo de híbridos que apresentou a melhor qualidade de fibra manteve esta característica até na época de corte mais avançada. Isto fica evidente, pois não houve interação significativa entre Grupos e Época de corte. Portanto, a seleção de híbridos baseados nesta característica para a produção de silagem pode ser realizada na época de corte $1 / 2 \mathrm{LL}$ (Tabela 3 ).

Melhores valores de degradabilidade da matéria seca foram encontrados por Mello et al. (2005) em híbridos com maiores teores de FDN degradável. Diversos trabalhos mostram ainda que num mesmo teor de fibra há diferença entre a FDN degradável, sendo esta capaz de promover um incremento na ingestão de matéria seca e produção de leite (Allen, 2003; Schwab et al., 2003 ). 
A FDN degradável do colmo apresentou valores de $32,8 \%$ e $31,5 \%$ para os grupos de alta e baixa respectivamente. Quanto as épocas de corte os valores para $1 / 2 \mathrm{LL}, 3 / 4 \mathrm{LL}$ e CN no grupo de alta foram respectivamente $21,6 \% 21 \%$ e $19,5 \%$. Já no grupo de baixa esses valores foram de $19,9 \%, 18,2 \%$ e $16,5 \%$.

A FDN degradável da folha não diferiu entre os grupos avaliados, sendo que na semeadura realizada em novembro as épocas de corte $1 / 2$ LL, 3/4 LL e CN apresentaram valores de FDN degradável de 39,9\%, 31,2\% e $31 \%$. Já para época de plantio em dezembro esses valores foram de $31,8 \%, 30 \%$ e $29,1 \%$ (Tabela 3). No plantio realizado em dezembro a FDN degradável na $1 / 2$ LL foi menor do que o plantio realizado em novembro. Esta característica não se mostrou interessante para o melhoramento de híbridos para produção silagem, pois não houve diferença significativa entre os grupos estudados. Portanto, a FDN degradável de folha pouco influenciou a degradabilidade da fração vegetativa dos grupos. Dentre a qualidade da fibra das frações avaliadas (Planta inteira, colmo, folha, palha e sabugo) a qualidade da fibra da folha foi a melhor para ambos os grupos.

$\mathrm{Na}$ fração palha a FDN degradável não diferiu entre os grupos avaliados. Para semeadura realizada em novembro os valores da FDN degradável na $1 / 2 \quad$ LL, $3 / 4$ LL e CN foram de $33,6 \%, 28,1 \%$ e $25,5 \%$. Já em dezembro para as mesmas épocas de corte esses valores foram de $30,0 \%, 26,3 \%$ e $27,9 \%$ (Tabela 3). Assim como a palha esta característica não se mostrou interessante para atuar no melhoramento visando seleção de híbridos para a produção de silagem, pois não houve variação significativa entre os grupos estudados e ao contrário de folha que apresentou uma FDN degradável média de $32,18 \%$ a palha teve uma FDN degradável média de $28,5 \%$ que junto com sabugo e colmo que obtiveram médias de $20,2 \%$ e $19,5 \%$, respectivamente, foram as piores qualidades de fibra encontradas (Tabela 2).
As médias do teor de FDN degradável da fração sabugo não diferiram entre os grupos de alta e baixa degradabilidade das frações vegetativas. Quanto as épocas de corte $1 / 2 \mathrm{LL}, 3 / 4 \mathrm{LL}$ e $\mathrm{CN}$ a FDN degradável do sabugo apresentou médias de 17,8\%, 19,9\% e $19,5 \%$ para semeadura realizada em novembro e valores de $27,4 \%, 19,7 \%$ e $17,33 \%$ para a semeadura realizada em dezembro.

A diferença da FDN Degradável entre os grupos de alta e baixa degradabilidade da fração vegetativa foram 1.73, 2.55, 1.31 e 0.13 unidades percentuais para a planta inteira, colmo, folha, palha e sabugo respectivamente (Tabela 2). A maior diferença foi encontrada na fração colmo 2.55 unidades percentuais. Este resultado demonstra a variabilidade existente na qualidade da fração colmo e a oportunidade para o melhoramento trabalhar este caráter afim de se obter híbridos com melhores qualidades para a produção de silagem. Kuehn et al. (1997) também encontraram menores valores de FDN degradável para a fração sabugo e palha corroborando com os dados obtidos neste trabalho.

Há na literatura uma carência de informações sobre qualidade de fibras dos componentes vegetativos da planta de milho, portanto este trabalho vem acrescentar e contribuir para que futuros experimentos possam explorar melhor esta excelente ferramenta para a seleção de híbridos para produção de forragem.

\section{CONCLUSÕES}

$\mathrm{O}$ avanço na maturidade afeta DEG, FDN e FDN degradável da planta inteira e seus componentes, exceto para FDN degradável de colmo.

Os grupos de alta degradabilidade dos componentes vegetativos apresentam melhores valores de DEG, FDN e FDN degradável para todas as frações exceto FDN de palha, FDN degradável de folha e FDN degradável de palha que não apresentaram diferenças entre os grupos avaliados. 
A interação não significativa entre Grupos $\mathrm{X}$ épocas de corte para todas as variáveis evidencia melhor qualidade dos híbridos de alta degradabilidade dos componentes vegetativos ao longo do avanço da maturidade da planta.

$\mathrm{O}$ atraso na semeadura afetou a degradabilidade dos componentes folha, palha e grãos, além dos teores de FDN de palha, sabugo e FDN degradável de folha. Porém não alterou os parâmetros associados a planta inteira.

\section{LITERATURA CITADA.}

ALLEN, M.S.; COORS, J.G.; ROTH, G.W. In: BUXTON, D. R.; MUCK, R. E.; HARRISON, J. H. (Eds.). Silage science and technology. Madison, WI: ASA-CSSASSSA. 2003. pp. 547-608.

BELEZE, J. R. F.; ZEOULA, L.M.I.; CECATO, U. et al. Avaliação de cinco híbridos de milho (Zea mays, L.) em diferentes estádios de maturação. 1. Produtividade, características morfológicas e correlações. Revista Brasileira de Zootecnia, Viçosa,vol. 32, $\mathrm{n}^{\mathrm{o}} 3$, p.529-537, 2003.

CAETANO, H. Avaliação de onze cultivares de milho colhidos em duas alturas de corte para produção de silagem. Jaboticabal, 2001. 178p. Tese (Doutorado) - Faculdade de ciências agrárias e veterinárias. Universidade Estadual Paulista "Júlio de Mesquita Filho".

CORREA, C.E.S.; SHAVER, R.D.; PEREIRA, M.N.; LAUER, J.G.; KOHN, K. Relationship between corn vitreousness and ruminal in situ degradability. Journal of Dairy Science, v.85, p.3008-3012, 2002.

ESTRADA-FLORES，J.G.; GONZÁLEZRONQUILLO, M.; MOULD, F.L. et al. Chemical composition and fermentation characteristics of grain and different parts of the stover from maize land races harvested at different growing periods in two zones of central Mexico. Animal Science, v.82, p.845-852, 2006.

KUEHN, C.S., LINN, J.G., JOHNSON, D.G., JUNG, H.G. Effect of feeding corn hybrids selected for leafiness or grain to lactating dairy cattle. Research Summaries, US Dairy Forage Research Center, 1997, Madison, USA, pp 220-230.

MELLO, R.; NÖRNBERG, J.L.; ROCHA, M.G. et al. Características produtivas e qualitativas de híbridos de milho para produção de silagem. Revista Brasileira de Milho e Sorgo, v.4, n.1, p.79-94, 2005.

PEREIRA, M. N. Response of lactating cows to dietary fiber from alfafa or cereal byproducts. 1997. 186 p. Thesis (PhD) Universty of Wisconsin, Madison.

PEREIRA, M. N.; VON PINHO, R. G.; SILVA, R.G.; CALESTINE, G.A.Ruminal degradability of hard or soft texture corn grain at three maturity stages. Sci. agric. (Piracicaba, Braz.), Piracicaba, v. 61, n. 4, 2004.

VAN SOEST, P. J.; ROBERTSON, J. B.; LEWIS, B. A. Methods for dietary fiber, neutral detergent fiber and nonstarch polysaccharides in relation to animal nutrition. Journal of Dairy Science, v.74, p.3583-3597, 1991

VERBIC, J.; STEKAR, J. M.A.; CEPON, M.R. Rumen degradation characteristics and fibre composition of various morphological parts of different maize hybrids and possible consequences for breeding. Animal Feed Science and Technology, v. 54, n.1, p.133-148, 1995.

SCHWAB, E.C., SHAVER, R.D., LAUER, J.G. et al. Estimating silage energy value and milk yield to rank corn hybrids. Journal of Animal Feed Science and Technology, v.109, n. 1, 1-18, 2003. 